\title{
Removal of Zn (II) and Cu (II) lons from Aqueous Solution by Dried Prosopis JULIFLORA
}

\author{
Million Mulugeta Habtegebrel ${ }^{1,}$, , Masood Akhtar Khan ${ }^{2}$ \\ ${ }^{1}$ Department of Chemistry, College of Natural and Computational Sciences, Kotebe Metropolitan University, Addis Ababa, Ethiopia \\ ${ }^{2}$ Department of Chemistry, College of Natural Sciences, Arba Minch University, Arba Minch, Ethiopia
}

Email address:

millionppp@gmail.com (M. M. Habtegebrel), Masood.akhtar19@gmail.com (M. A. Khan)

${ }^{*}$ Corresponding author

\section{To cite this article:}

Million Mulugeta Habtegebrel, Masood Akhtar Khan. Removal of Zn (II) and Cu (II) Ions from Aqueous Solution by Dried Prosopis JULIFLORA. Modern Chemistry. Vol. 6, No. 1, 2018, pp. 6-14. doi: 10.11648/j.mc.20180601.12

Received: March 10, 2017; Accepted: March 21, 2017; Published: February 27, 2018

\begin{abstract}
The use of cheap and ecofriendly adsorbents was been studied to find an alternative substitution of activated carbon for the removal heavy metals from wastewater. Prosopis juliflora is an invasive weed which posing a great environmental threat to other flora all over the world. In this study, the influence of physico-chemical key parameters such as the solution $\mathrm{pH}$, the contact time, adsorbent dose, etc. The obtained experimental results have been fitted according to the two known adsorption models of Langmuir and Freundlich. The adsorption best fits the Langumir adsorption isotherm, which shows homogenous nature of adsorption. Prosopis juliflora can be a novel adsorbent according to results obtained in this study on the adsorbent dried prosofis juliflora. It is recommendable to use this weed as an adsorbent as it is obvious of solving two problems with one cure in the environment.
\end{abstract}

Keywords: Adsorption, Prosofis, $\mathrm{Cu}, \mathrm{Zn}$, Heavy Metals

\section{Introduction}

Heavy metals are any element in the $d$-block of the periodic table or transition metals that have specific gravities at least five times the specific gravity of water. Examples include iron $(\mathrm{Fe})$, cobalt $(\mathrm{Co})$, chromium $(\mathrm{Cr})$, copper $(\mathrm{Cu})$, zinc $(\mathrm{Zn})$, silver $(\mathrm{Ag})$ and cadmium $(\mathrm{Cd})$ [1]. Many are known to be toxic to both humans and other living forms at lower concentration. It is well perceived that there is a permissible limit of each metal, above which It is generally toxic [2] and some are even hazardous, their accumulation over time causing headache dizziness, respiratory difficulty, hemolytic anemia, massive gastrointestinal bleeding, liver and kidney failure and death [3].

Most of these metals were present in our environment only in minute amounts until recent centuries, when the orientation toward industrialization and production brought about our many technological advances. At present, these toxic metals have polluted our atmosphere, waters, soil, and food chain [4]. Heavy metal pollution derives from a number of industries such as electroplating, pharmaceutical, metal purification, preparation of nuclear fuels, electroplating, mining, tanneries, painting, car radiator manufacturing as well as agricultural sources where fertilizers and fungicidal spray intensively used [5].

Unlike organic contaminants, heavy metals do not normally undergo biological decay and are thus considered a challenge for remediation. Many governments have enacted laws to hinder discharging heavy metals into water bodies and using toxic substances such as lead [6]. However, heavy metals still find their way to water supplies. Accordingly, many studies have been done for removal of heavy metals including chemical precipitation, ion exchange, reverse osmosis and ultra filtration are among the commonly used in industries. However, these technologies are becoming uneconomical and unfavorable (some of them produce large toxic sludge like precipitation) to remove heavy metals from industrial wastewaters [7]. As a result the effluent treatment in developing countries is expensive. The indigenous production of treatment techniques that use locally available 
non-conventional materials to treat pollutants seems to be the solution to the increasing problem of treatment of effluents so that searching for a low cost and easily available adsorbent has led to the selection of materials from agricultural and biological origin as adsorbents. That is biosorption.

Biosorption can be defined as removal of metallic ion by means of passive adsorption and complexation by living biomass or organic waste [8]. Biosorption is a process in which solids of natural origin are employed for binding of heavy metals. It is the physico - chemical binding of metal species in biomass [9]. More specially, the metal binding in biosorption may be due to a combination of several sequestering mechanisms such as complexing, co-ordination, chelation, adsorption, ion exchange [10].

The main advantage of using biosorption technology is the cost effectiveness of using the biosorbent, since it may be derived from various cheap raw materials [8]. Besides this, biosorption offers advantages of low operating cost, minimizes the volume of chemical, no toxic sludge produced at the end of the process (because it can be recycled), no additonal nutrient requirement, regeneration of the biosorbent, possibility of metal recovery and is highly efficient in matal ion removal from dilute solution [11]. These advantages served as potential incentives for promoting biosorption as a viable clean-up technology for heavy metals pollution.

Various waste biomaterials such as grape stalk waste [12], green coconut shell powder [13], chaff [14], crab shell particles [15] and rice husk, walnut hull, mango seed husks, sawdust, sugarcane bagasse, sugar beet pulp, coffee husk [16] have been studied for the removal of heavy metal ions from the effluents. In addition to biomaterials, microorganisms have also been used as metal sorbents. Eichhornia crassipes has been reported to remove heavy metals from aqueous solutions [17].

Prosopis species is one of the highly invasive plants in the world. Among the 45 recognized Prosopis species [18], Prosopis glandulosa, P. velutina, P. juliflora and P. pallida are reported to be generally problematic [19]. Prosopis has invaded millions of hectares of land in the arid and semi-arid continents of Asia, Africa, Australia and Americas. In Africa alone, Prosopis is believed to have invaded over 4 million hectares, threatening crop and rangeland production, desiccating water resources and displacing native flora and fauna [20].

However, no previous study have been reported on the application of Prosopis juliflora for wastewater treatment purposes for $\mathrm{Zn}$ (II) and $\mathrm{Cu}$ (II) ions removal So that the aim of this research is to investigate the use of powdered Prosopis juliflo rain the removal of $\mathrm{Zn}$ (II) and $\mathrm{Cu}$ (II) ions from aqueous solutions. Using these alien weed as biosorbent can be an alternative way to monitor the spreading in the environment to some extent.

General Objective

1) The general objective of this study was to investigate the adsorption efficiency of untreated dried Prosopis juliflora for the removal of $\mathrm{Zn}$ (II) and $\mathrm{Cu}$ (II) ions from aqueous solution.

Specific Objectives

1) To investigate the removal efficiency of dried Prosopis juliflora for $\mathrm{Zn}$ (II) and $\mathrm{Cu}$ (II) ions from aqueous solution.

2) Determination of the effects of contact time, adsorbent dosage, $\mathrm{pH}$ and initial metal ion concentrations on $\mathrm{Zn}$ (II) and $\mathrm{Cu}$ (II) ions removal efficiency of untreated dried Prosopis juliflora.

3) To plot the Langmuir and Freundlich isotherms and explain the nature of adsorption.

\section{Materials and Methods}

\subsection{Apparatus and Materials}

\subsubsection{Apparatus}

The Apparatus used in this study were: FAAS(MP 220) to measure metal ion concentration, Rotary shaker (Orbital shaker SO1, UK) to agitate the sample, $\mathrm{pH}$ meter(MP 220) to measure $\mathrm{pH}$ of the solution, Electronic balance (OHAUS, Swizerland) for weighting, Erlenmeyer flasks, Magnetic stirrer for stirring solution, Desiccator (Nikko Japan super dry SD-504) to keep a sample less humid, Electrical mill (IKA WERKE) to grind sample, Whatman No-1 (125mm) filter paper, Sieve to get $1 \mathrm{~mm}$ particle size, Hot Air Oven (Contherm 260M) to dry sample and fridge.

\subsubsection{Chemicals and Reagents}

Analytical grade reagents; $\mathrm{CuSO}_{4} .5 \mathrm{H}_{2} \mathrm{O}$ and $\mathrm{ZnSO}_{4} .7 \mathrm{H}_{2} \mathrm{O}$ (Blulux Laboratories Pvt. Ltd-op) were used to prepare standard solutions of the metals studied. Concentrated $\mathrm{HNO}_{3}, \mathrm{NaOH}, \mathrm{HCl}$ (Blulux Laboratories (p) Ltd- 121001) and buffer solutions (E. Merck) solution were also used.

\subsection{Experimental Methods and Procedures}

\subsubsection{Cleaning Sampling Equipment}

All plastic bags, polyethylene bottles, plastic bottles, plastic scoops and glasswares were thoroughly washed with detergent, rinsed with water and then with distilled water before soaking in to $\mathrm{HNO}_{3}$ for about 24 hours. Containers were finally rinsed with deionized water before being used for sampling.

\subsubsection{Experimental Site}

This study was be carried out by collecting Prosopis juliflora Arba Minch city, Ethiopia which is located $500 \mathrm{KM}$ away from Addis Ababa the capital city of Ethiopia.

\subsubsection{Preparation of Biosorbent (Dried Prosopis Juliflora)}

The Prosopis juliflora was collected from experimental site using plastic bugs and was powdered and sieved to get uniform size (50-100) mesh particle size. Then it washed with distilled water to remove dirt and was boiled to remove color, and dried at $105^{\circ} \mathrm{C}$ for $5 \mathrm{~h}$ in a convection oven and stored in sealed plastic bags prior to study. 


\subsubsection{Preparation of Adsorbate Solutions (Synthetic Solution)}

Stock standard solutions, having concentrations of 1000 $\mathrm{mg} / \mathrm{L}$, of $\mathrm{Cu}$ (II) and $\mathrm{Zn}$ (II) ions were prepared by dissolving $3.93 \mathrm{~g}$ of copper sulfate $\left(\mathrm{CuSO}_{4} .5 \mathrm{H}_{2} \mathrm{O}\right)$ and $4.4 \mathrm{~g}$ of Zinc sulfate $\left(\mathrm{ZnSO}_{4} .7 \mathrm{H}_{2} \mathrm{O}\right)$ respectively in $1 \mathrm{~L}$ volumetric flask and diluted to the mark with double de-ionized water to avoid errors in the results. Finally, small drops of concentrated nitric acid solution was added to each stock solution to avoid precipitate formation and these solutions were used to prepare working solutions of various concentrations by appropriate dilution. Standard solutions of both metal ions were prepared by diluting secondary stock solution of 50 $\mathrm{mg} / \mathrm{L}$.

\subsection{Batch Mode Adsorption Studies}

Batch mode adsorption studies for individual metal ions were carried out using $250 \mathrm{~mL}$ Erlenmeyer flask. The effects of different parameters such as adsorbent dose, $\mathrm{pH}$, contact time and adsorbate concentration were studied. The Erlenmeyer flasks were pretreated with the respective adsorbate for 24 hours to avoid adsorption of the adsorbate on the container walls. Standard solutions of the metal ions were mixed with the Prosopis juliflora powder and agitated at $120 \mathrm{rpm}$ on a mechanical shaker. This was carried out by varying the metal ion concentrations, contact time, $\mathrm{pH}$ and the mass of Prosopis juliflora powder used for adsorption. Finally, the resulting suspension of each of the metal ions was filtered using a Whatman No.1 filter paper and the filtrate was analyzed for the corresponding metal ion concentration. Removal efficiency was finally calculated by using the relationship in equation 1 .

$$
\text { Adsorption }(\%)=\left(\left(\mathrm{Co}-\mathrm{C}_{\mathrm{e}}\right) / \mathrm{Co}\right) \times 100
$$

Where $\mathrm{Co}=$ the initial concentration $(\mathrm{mg} / \mathrm{L})$ and $\mathrm{C}_{\mathrm{e}}=$ final concentration $(\mathrm{mg} / \mathrm{L})$ of the metal ions being studied. Adsorption capacity of the Prosopis juliflora powder is the concentration of the metal ion on the adsorbent mass and was calculated based on the mass balance principle [21].

$$
\mathrm{q}_{\mathrm{e}}=\left(\mathrm{Co}-\mathrm{C}_{\mathrm{e}}\right) \times \mathrm{V} / \mathrm{M}
$$

Where $\mathrm{q}_{\mathrm{e}}=$ adsorption capacity of Prosopis juliflora $(\mathrm{mg} / \mathrm{g})$ $\mathrm{V}=$ the volume of reaction mixture $(\mathrm{L})$

$\mathrm{M}=$ the mass of adsorbent used $(\mathrm{g})$

$\mathrm{Co}=$ the initial concentration $(\mathrm{mg} / \mathrm{L})$ of the metal ions and

$\mathrm{C}_{\mathrm{e}}=$ final concentration $(\mathrm{mg} / \mathrm{L})$ of the metal ions

\subsubsection{Effect of Contact Time}

Contact time is one of the most important parameters for the assessment of practical application of sorption process (Shan et al 2007). For the determination of the rate of $\mathrm{Cu}$ (II) and $\mathrm{Zn}$ (II) ions biosorption by the Prosopis juliflorapowder from $100 \mathrm{~mL}$ of standard solutions, the quantity of metal ions adsorbed was determined by varying the contact time: (30, $60,90,120$ and $150 \mathrm{~min})$. Other parameters were kept constant.

\subsubsection{Effect of Adsorbent Dosage}

The effect of adsorbent dosage was studied by using $0.5,1$, 2, 3, 4 and $5 \mathrm{~g}$ of Prosopis juliflora in $250 \mathrm{~mL}$ Erlenmeyer flasks with metal ion concentration of $50 \mathrm{mg} / \mathrm{L}$ and the adsorption efficiency for different doses was determined by keeping other parameters constant.

\subsubsection{Effect of $\mathrm{pH}$}

The effect of $\mathrm{pH}$ on the biosorption of metal ions was studied within the range that will not be influenced by the metal precipitated [22]. To determine the effect of solution acidity on the efficiency of adsorption, $\mathrm{pH}$ of the solutions were adjusted between 1-8 and 2-9 for $\mathrm{Cu}$ (II) and $\mathrm{Zn}$ (II) ions respectively and adsorption experiments were carried out by keeping other parameters constant.

\subsubsection{Effect of Initial Concentration}

This step determines the effect of metal ions concentration on metal ions removal efficiency of adsorbent (Prosopis juliflora powder). The effect of metal ions concentration was determined using concentrations of $10 \mathrm{mg} / \mathrm{L}, 30 \mathrm{mg} / \mathrm{L}, 50$ $\mathrm{mg} / \mathrm{L}, 70 \mathrm{mg} / \mathrm{L}, 90 \mathrm{mg} / \mathrm{L}$ and $100 \mathrm{mg} / \mathrm{L}$ for each metal ions and keeping other parameters constant.

\subsection{Data Analysis and Interpretation}

The data generated were analyzed by using Microsoft Excel to compute the mean, standard deviation and linear regression values.

\section{Results and Discussion}

\subsection{The Optimum Condition for $\mathrm{Cu}$ (II) and Zn (II) Ions Removal by Prosopis Juliflora}

\subsubsection{Effect of Adsorbent Dosage}

The effect of the adsorbent dose was studied at room temperature using different adsorbent doses of $0.5 \mathrm{~g}, 1 \mathrm{~g}, 2 \mathrm{~g}$, $3 \mathrm{~g}, 4 \mathrm{~g}$ and $5 \mathrm{~g}$. For all these runs, initial concentration of both $\mathrm{Cu}$ (II) and $\mathrm{Zn}$ (II) ions, $\mathrm{pH}$ of solutions, agitation speed and contact time were kept constant. Figures 1 and 2 show the effect of adsorbent dosage on the adsorption of $\mathrm{Cu}$ (II) and $\mathrm{Zn}$ (II) ions respectively.

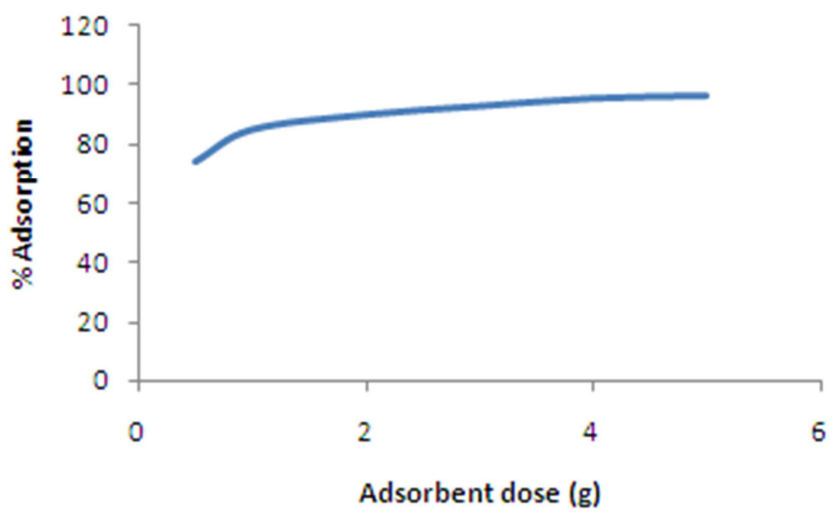

Figure 1. $C u(I I)$ ions removal efficiency (\%) (Initial concentration $=50$ $m g / L$, contact time $=90 \mathrm{~min}$, solution $\mathrm{pH}=5$, agitation speed $=120 \mathrm{rpm}$ ). 


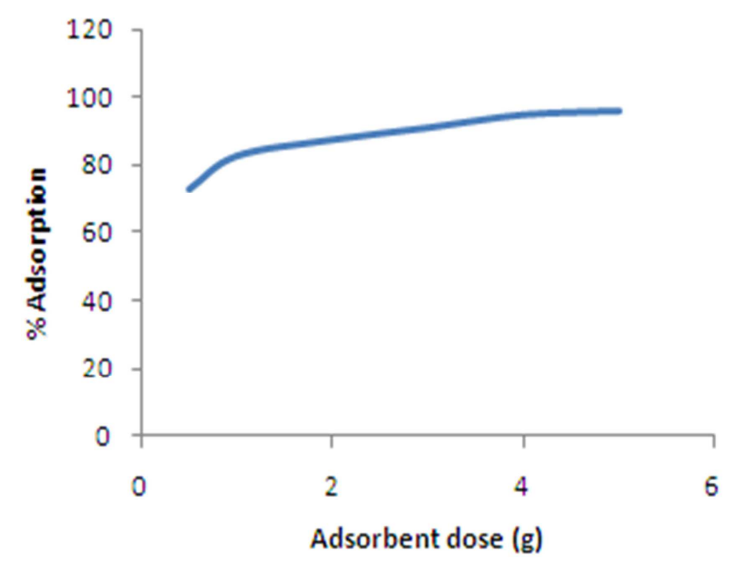

Figure 2. $\mathrm{Zn}(\mathrm{II})$ ions removal efficiency (\%) (Co $=50 \mathrm{mg} / \mathrm{L}$, contact time $=$ $90 \mathrm{~min}$, solution $\mathrm{pH}=6$, agitation speed $=120 \mathrm{rpm}$ ).

In both cases adsorption efficiency increased with adsorbent dose in the range from 0.5- $1 \mathrm{~g}$ and showed little variation with further increment. This trend was found to be similar for both metal ions and may be due to the saturation of sorption sites at higher biosorbent concentration. This indicates that removal efficiency is directly related to the number of available adsorption sites [23]. Biosorbent quantity is therefore, very essential because it determines the capacity of biosorbent for removal of a particular metal ion from solution. The results show that the adsorption capacity decreased from 7.45 to $0.97 \mathrm{mg} / \mathrm{g}$ for $\mathrm{Cu}$ (II) and from 7.26 to $0.96 \mathrm{mg} / \mathrm{g}$ for $\mathrm{Zn}$ (II) ions however, percentage absorption increased from $74.54 \%$ to 96.76 for $\mathrm{Cu}(\mathrm{II})$ and from 72.64 to $96.26 \%$ for $\mathrm{Zn}$ (II) with increase in the dose of drired Prosopis juliflora from $0.5-5 \mathrm{~g}$. These results are in agreement with studies by [24]. In all subsequent studies, $1.0 \mathrm{~g}$ of the sorbent was taken as optimum dosage.

\subsubsection{Effect of Contact Time}

To determine the optimum contact time for $\mathrm{Cu}$ (II) and $\mathrm{Zn}$ (II) ions adsorption, $50 \mathrm{mg} / \mathrm{L}$ solution of both ions was added into $1.0 \mathrm{~g}$ of Prosopis juliflora adsorbent and agitated by varying the contact time from 30 to 150 minutes at 30 minutes interval. The results obtained are given in Figures 3 and 4 .

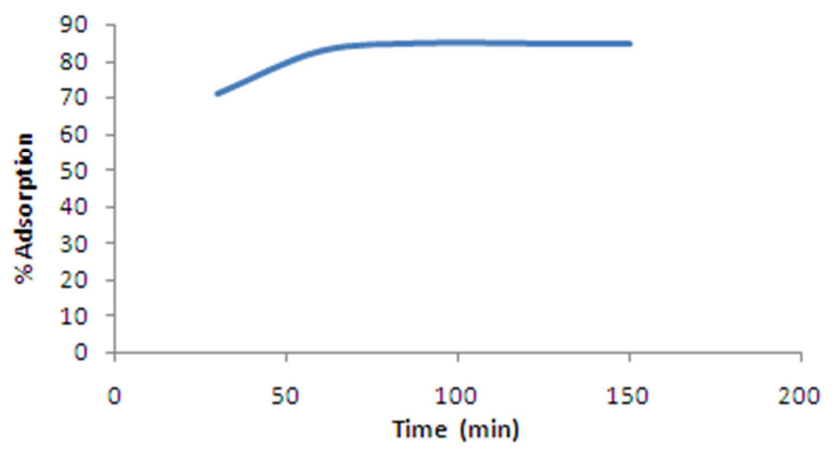

Figure 3. $\mathrm{Cu}(\mathrm{II})$ ions removal efficiency (\%) at various contact time (Co= $50 \mathrm{mg} / \mathrm{L}$, dose $=1.0 \mathrm{~g}$, solution $\mathrm{pH}=5$, agitation speed $=120 \mathrm{rpm})$.

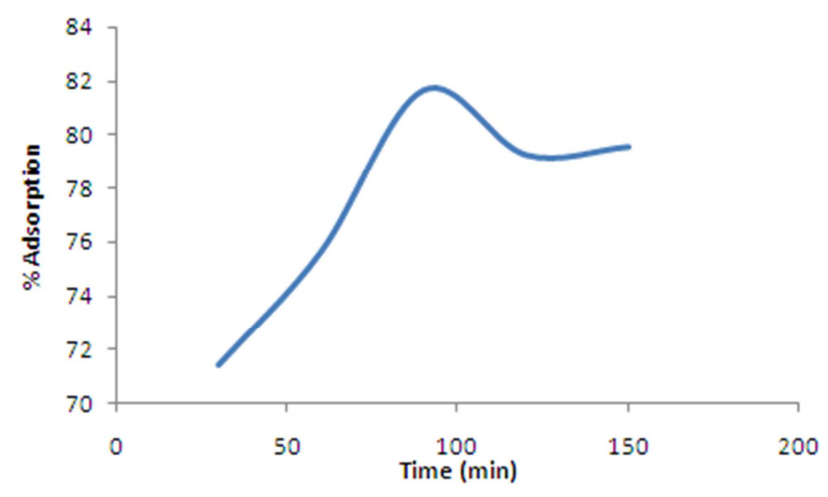

Figure 4. $\mathrm{Zn}(\mathrm{II})$ ions removal efficiency (\%) at various contact time (Co = $50 \mathrm{mg} / \mathrm{L}$, dose $=1.0 \mathrm{~g}$, solution $\mathrm{pH}=6$, agitation speed $=120 \mathrm{rpm}$ ).

The results clearly revealed that adsorption process took place in two stages. Rate of adsorption was higher at the first stage, where about $85.12 \%$ and $81.66 \%$ of adsorption were completed for $\mathrm{Cu}$ (II) and $\mathrm{Zn}$ (II) ions respectively. This is due to availability of a large number of active sites on the adsorbent. As these sites are exhausted, the uptake rate was controlled in the second stage at which the adsorbate is transported from the exterior to the interior sites of the adsorbent particles. This is in accordance with the observations of other similar studies [25]. The removal efficiency turned sharply at contact time of 90 minutes for both $\mathrm{Cu}$ (II) and $\mathrm{Zn}$ (II) ions. At these points, the amount of the respective metal ions adsorbed on the sorbent was in a state of dynamic equilibrium with the amount of metal ions desorbed from sorbent and the increment became stable. Due to this reason the optimum contact time for both metal ions were taken as 90 minutes for the subsequent investigations.

\subsubsection{Effect of $\mathrm{pH}$}

The effect of $\mathrm{pH}$ on the extent of adsorption of $\mathrm{Cu}$ (II) and $\mathrm{Zn}$ (II) ions on the Prosopis juliflora powder was studied by varying the $\mathrm{pH}$ in the range of $1.0-8.0$ and $2.0-9.0$ for the two metal ions respectively. At metal ions concentration 50 $\mathrm{mg} / \mathrm{L}$ and agitation speed of $120 \mathrm{rpm}$, the contact time for both $\mathrm{Cu}$ (II) and $\mathrm{Zn}$ (II) ions was set at $90 \mathrm{~min}$. The results obtained are illustrated in Figures 5 and 6.

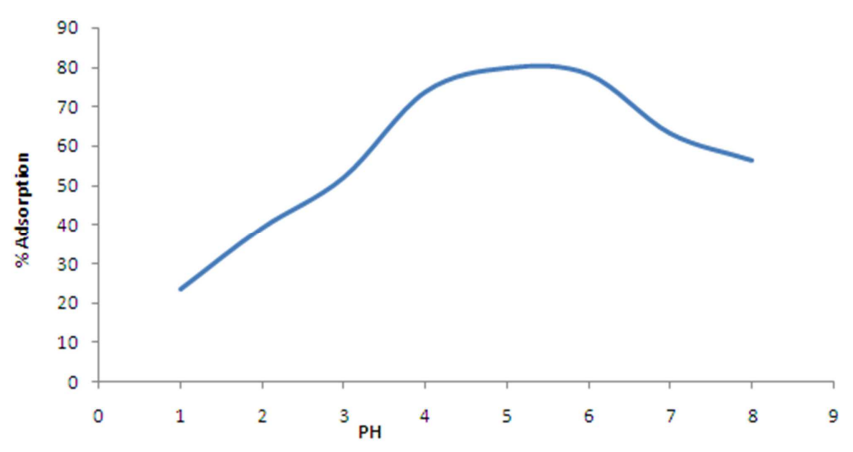

Figure 5. Effect of pH on Cu(II) ions removal efficiency (\%) (Co $=50 \mathrm{mg} / \mathrm{L}$, dose $=1 \mathrm{~g}$, time $=90 \mathrm{~min}$, agitation speed $=120 \mathrm{rpm}$ ).

Figure 5 shows that the maximum percent removal of $\mathrm{Cu}$ (II) ions on the adsorbents was observed at $\mathrm{pH} 4-5$ and 
significantly decreased by reducing the $\mathrm{pH}$ values and slightly decreased at higher $\mathrm{pH}$ values. The removal efficiency increased from $23.5 \%$ to $79.82 \%$ as $\mathrm{pH}$ increased from 1 to 5 ; therefore, optimal metal ions removal efficiency occurs at $\mathrm{pH} 5$. The maximum percent removal of zinc ions was observed at $\mathrm{pH} 4-6$ as shown in Figure 6, and significantly decreased at lower $\mathrm{pH}$ value. The removal efficiency increased from $27.66 \%$ to $78.04 \%$ as $\mathrm{pH}$ increased from 2 to 6 ; hence $\mathrm{pH} 6$ was fixed as optimal $\mathrm{pH}$ value for further investigations. According to [26], little sorption at lower $\mathrm{pH}$ could be ascribed to the hydrogen ions competing with metal ions for sorption sites. This means that at higher $\mathrm{H}^{+}$concentration, the biosorbent surface becomes more positively charged, thus, reducing the attraction between adsorbent and metal ions. In contrast, as the $\mathrm{pH}$ increases, more negatively charged surface become available, thus facilitating greater metal ions uptake $[21,26]$. At a higher $\mathrm{pH}$, the $\mathrm{Cu}(\mathrm{II})$ and $\mathrm{Zn}$ (II) ions precipitated as their hydroxides which decreased the rate of adsorption and subsequently the percent removal of metal ions.

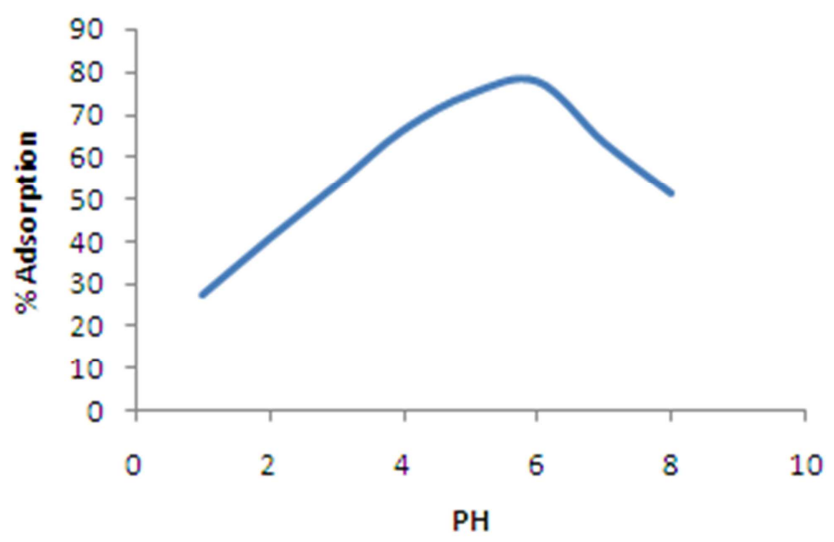

Figure 6. Effect of $\mathrm{pH}$ on $\mathrm{Zn}(\mathrm{II})$ ions removal efficiency (\%) (Co $=50 \mathrm{mg} / \mathrm{L}$, dose $=1 \mathrm{~g}$, time $=90 \mathrm{~min}$, agitation speed $=120 \mathrm{rpm}$ ).

The decrease in the adsorption rate in the $\mathrm{pH}$ range from 5 to 8 for $\mathrm{Cu}$ (II) and 6 to 9 for $\mathrm{Zn}$ (II) ions might be attributed to the formation of $\mathrm{Cu}(\mathrm{OH})_{3}{ }^{-}$and $\mathrm{Zn}(\mathrm{OH})_{3}{ }^{-}$ions taking place as a result of dissolution of $\mathrm{Cu}(\mathrm{OH})_{2}$ and $\mathrm{Zn}(\mathrm{OH})_{2}$ respectively. This is attributed to the adsorbent surface being negative at the above $\mathrm{pH}$ range, which cannot absorb the negatively charged ions $\mathrm{Cu}(\mathrm{OH})_{3}{ }^{-}$and $\mathrm{Zn}(\mathrm{OH})_{3}{ }^{-}$ respectively, rather than repel each other.

\subsubsection{Effect of Initial Concentration of Metal Ion}

The effect of initial concentration of metal ions on the extent of adsorption of $\mathrm{Cu}$ (II) and $\mathrm{Zn}$ (II) ions on the Prosopis juliflora powder was studied using the initial concentration of metal ions of $10 \mathrm{mg} / \mathrm{L}, 30 \mathrm{mg} / \mathrm{L}, 50 \mathrm{mg} / \mathrm{L}$, $70 \mathrm{mg} / \mathrm{L}, 90 \mathrm{mg} / \mathrm{L}$ and $100 \mathrm{mg} / \mathrm{L}$ with contact time of $90 \mathrm{~min}$, agitation speed of $120 \mathrm{rpm}$ and $\mathrm{pH}$ of 5 for $\mathrm{Cu}$ (II) and 6 for $\mathrm{Zn}$ (II) ions. The results obtained are illustrated in Figures 7 and 8 .

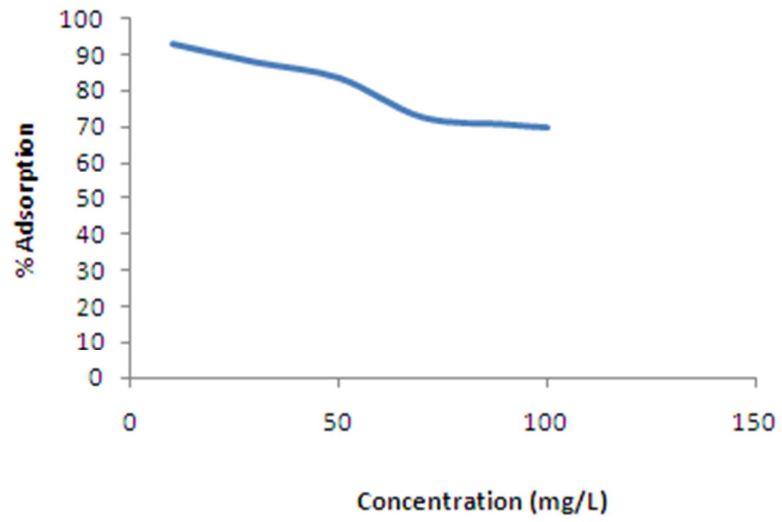

Figure 7. Effect of initial concentration on $\mathrm{Cu}(\mathrm{II})$ ions removal efficiency $(\%)(P H=5$, dose $=1 \mathrm{~g}$, time $=90 \mathrm{~min}$, agitation speed $=120 \mathrm{rpm})$.

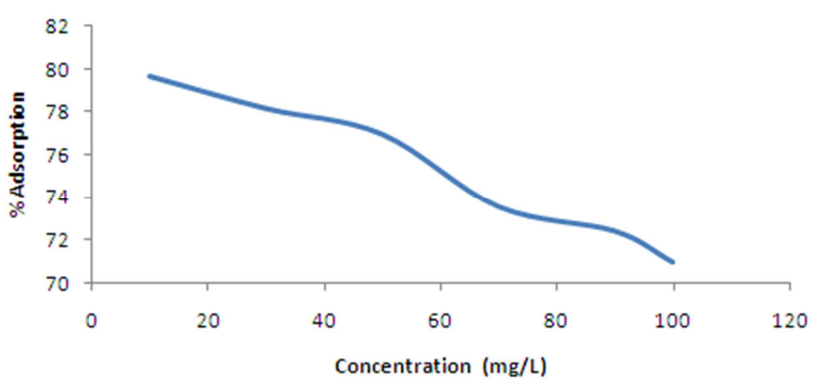

Figure 8. Effect of initial concentration on Zn(II) ions removal efficiency $(\%)(P H=6$, dose $=2 \mathrm{~g}$, time $=90 \mathrm{~min}$, agitation speed $=120 \mathrm{rpm})$

At lower concentration (10 to $30 \mathrm{mg} / \mathrm{L})$, ratio of the initial moles of metal ions to the available adsorption sites was low and subsequently the fractional sorption became independent of initial metal ions concentration. However, at higher concentration of $\mathrm{Cu}$ (II) and $\mathrm{Zn}$ (II) ions, the available sites for sorption became fewer compared to the moles of metal ions present and hence the percentage adsorption of the metal ions would be dependent upon the initial metal ions concentration. The result indicates that percentage $\mathrm{Cu}$ (II) and $\mathrm{Zn}$ (II) ions removal decreases as the initial concentration of both metal ions was increased. $\mathrm{Cu}$ (II) removal ranged from $83.82 \%$ to $69.67 \%$ and $\mathrm{Zn}$ (II) removal from $79.70 \%$ to $70.98 \%$ for the initial concentration of 10 $100 \mathrm{mg} / \mathrm{L}$ for both metal ions. This can be explained by the fact that all the adsorbents had a limited number of active sites, which would have become saturated above a certain concentration (Yu et al., 2003). Since $\% R=\left(C^{\mathrm{o}}-\mathrm{C}^{\mathrm{e}}\right) / \mathrm{C}^{\mathrm{o}}$, another reason for decrease in percent removal is larger increase in the denominator $\left(\mathrm{C}^{0}\right)$ value in comparison with that of the numerator $\left(\mathrm{C}^{\mathrm{o}}-\mathrm{C}^{\mathrm{e}}\right)$ value. In addition, the adsorption capacity (qe) of $\mathrm{Cu}$ (II) and $\mathrm{Zn}$ (II) ions removed (mg per gram) of the adsorbent is lager for higher concentration. For this reason, $50 \mathrm{mg} / \mathrm{L}$ was chosen as optimum initial concentration for both metal ions.

\subsection{Adsorption Isotherm}

Adsorption isotherm is needed to explain the adsorption process and to determine the adsorption efficiency of an adsorbent. Out of the different adsorption isotherm models, 
Langmuir's and Freundlich's model have been preferred by most of the studies concerning about adsorption. The present experiment also used Langmuir's and Freundlich's equations to explain the adsorption mechanism of the biosrbent considered.

\subsubsection{Cu(II) Ions Adsorption Isotherms}

Adsorption isotherm studies were carried out to determine an approximate value of adsorption capacity of an adsorbent using adsorbent doses of: $0.5,1,2,3,4$ and $5 \mathrm{~g}$. Using Langmuir's equation to analyze copper adsorption isotherm, the graph shows the relation between $1 / \mathrm{Ce}$ in the $\mathrm{x}$ axis and $1 /$ qe in the $y$ axis. On the other hand, the graph of Fruendlich's equation shows the relationship between $\log \mathrm{Ce}$ in the $\mathrm{X}$ axis and log qe in the $\mathrm{y}$ axis.

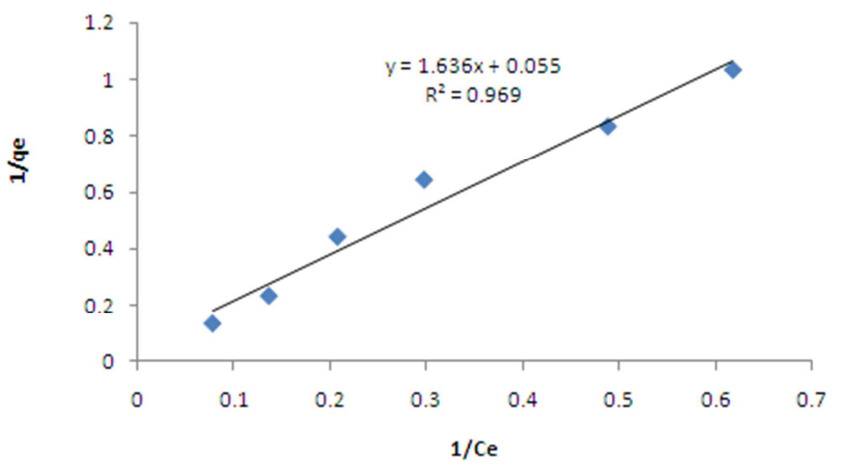

Figure 9. Langmuir adsorption isotherms for $\mathrm{Cu}(\mathrm{II})$ ions.

Langmuir adsorption isotherm model for Copper (II) ions

The Langmuir model assumes monolayer coverage of adsorbent surface and no interaction of adsorbate in the plane of the adsorbent surface. The empirical Langmuir equation is written as shown in equation 3 .

$$
\mathrm{qe}=\mathrm{q}_{\mathrm{m}} \mathrm{bCe} /(1+\mathrm{bCe})
$$

The linear form Langmuir isotherm is given by the following equation (Langmuir, 1918)

$$
\mathrm{Ce} / \mathrm{q}_{\mathrm{e}}=1 / \mathrm{bq}_{\mathrm{m}}+\mathrm{Ce} / \mathrm{q}_{\mathrm{m}}
$$

Another linear form can be obtained by dividing the above equation by $\mathrm{C}_{\mathrm{e}}$. Plotting $1 / \mathrm{q}_{\mathrm{m}}$ against $1 / \mathrm{Ce}$, astraight line is obtained having a slope $1 / \mathrm{bq}_{\mathrm{m}}$ and intercept $1 / \mathrm{q}_{\mathrm{m}}$.

$$
1 / \mathrm{e}=1 / \mathrm{q}_{\mathrm{m}}+1 / \mathrm{Ce}\left(1 / \mathrm{bq}_{\mathrm{m}}\right)
$$

According to Figure 9. Intercept $\mathrm{Y}\left(1 / \mathrm{q}_{\mathrm{m}}\right)=0.055, \mathrm{q}_{\mathrm{m}}=$ 18.18 , Slope $\left(1 / \mathrm{bq}_{\mathrm{m}}\right)=1.636, \mathrm{bq}_{\mathrm{m}}=0.6113$ and $\mathrm{qe}=$ $0.6113 \mathrm{Ce} /(1+0.0336 \mathrm{Ce})$

From the Langmiur's equation, the maximum adsorption capacity $\left(\mathrm{q}_{\mathrm{m}}\right)$ by Prosopis juliflora was $18.18 \mathrm{mg} / \mathrm{g}$. That is one gram of the Prosopis juliflora can adsorb $18.18 \mathrm{mg}$ copper. The essential characteristics of Langmuir isotherms can be expressed in terms of dimensionless equilibrium parameter $\mathrm{R}_{\mathrm{L}}$ (Juang, 1997).

$$
\mathrm{R}_{\mathrm{L}}=1 /(1+\mathrm{bCo})
$$

Where $\mathrm{Co}=$ initial metal ion concentration in solution $(\mathrm{mg} / \mathrm{l})$

$\mathrm{b}=$ characteristic constants related to adsorption energy

The parameter $\mathrm{R}_{\mathrm{L}}$ is also called the "separation factor" and provides a quantitative description of the equilibrium regions: $R_{L}=0$ for irreversible, $R_{L}<1$ for favourable, $R_{L}=1$ for linear, and $\mathrm{R}_{\mathrm{L}}>1$ for unfavourable adsorption. In our experiment, the value of $R_{L}=1 / 2.68=0.373$, which indicates a favorable adsorption. This means that Prosopis juliflora is a favourable adsorbent for the removal of $\mathrm{Cu}$ (II).

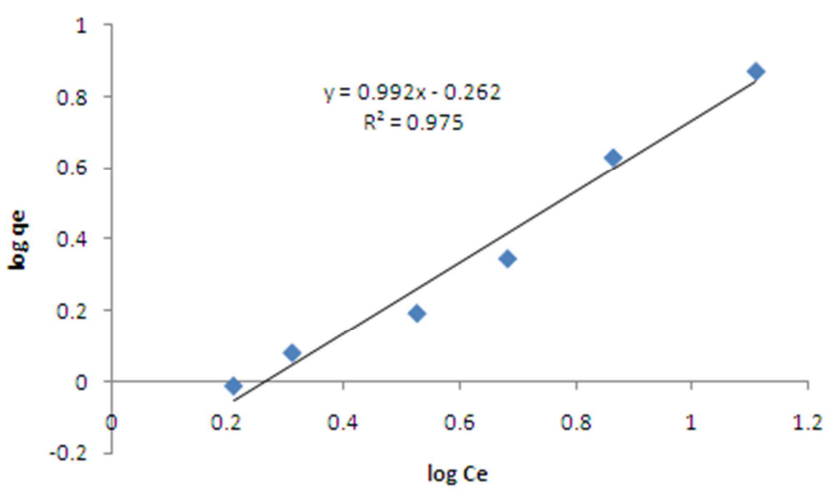

Figure 10. Freundlich adsorption isotherm for $\mathrm{Cu}(I I)$ ions.

Freundlich adsorption isotherm for copper (II) ions

The Freundlich adsorption equation is perhaps the most widely used mathematical description of adsorption in aqueous system. The Freundlich equation is expressed in equation 7:

$$
\mathrm{X} / \mathrm{M}=\mathrm{K}_{\mathrm{f}} \mathrm{Ce}^{1 / \mathrm{n}}
$$

Where $\mathrm{X}=$ the amount of solute adsorbed

$\mathrm{M}=$ the weight of adsorbent

$\mathrm{Ce}=$ the solute equilibrium concentration

$\mathrm{K}_{\mathrm{f}}=$ Freundlich adsorption capacity

$\mathrm{n}=$ Freundlich constant related to adsorption intensity

The Freundlich equation is an empirical expression that encompasses the heterogeneity of the surface and the exponential distribution of sites and their energies. For linearization of the equation, it can be written in logarithmic form [27].

$$
\log \mathrm{x} / \mathrm{m}=\log \mathrm{K}_{\mathrm{f}}+1 / \mathrm{n} \log \mathrm{Ce}
$$

Plotting $\log \mathrm{x} / \mathrm{m}$ versus $\log \mathrm{Ce}$, a straight line is obtained with a slope of $1 / \mathrm{n}$ and intercept of $\log \mathrm{Kf}$.

$$
\log \mathrm{x} / \mathrm{m}=\log \mathrm{K}_{\mathrm{f}}+1 / \mathrm{n} \log \mathrm{Ce}
$$

According to Figure 10:

Slope $1 / \mathrm{n}=0.992$

Intercept $\log \mathrm{K}_{\mathrm{f}}=-0.262$

Constant $\mathrm{K}_{\mathrm{f}}=0.547$

Freundlich's equation

$$
\mathrm{qe}=\mathrm{K}_{\mathrm{f}} \mathrm{Ce}^{1 / \mathrm{n}}=0.547 \mathrm{Ce} \mathrm{e}^{0.992}
$$

Another constant that was considered here was the value of $1 / \mathrm{n}$. This value shows the concentration of solute adsorption. If the value of $1 / \mathrm{n}$ is close to 1 , it shows that 
just a little concentration change can relatively affect the adsorption. Besides, $\mathrm{n}$ value can indicate the capacity of adsorption and the adsorbent dose. If $\mathrm{n}$ is more than 1 $(n>1)$, it means the adsorbent can effectively adsorb the solute. From freundlich equation the values of $1 / n$ and $n$ were obtained as 0.84 and 1.19 , respectively. Since the values of $1 / n$ lies between 0 and 1 and $n>1$, it indicates that the Prosopis juliflora can adsorb copper effectively.

The correlation coefficients $\left(\mathrm{R}^{2}\right)$ of Prosopis juliflora in Freundlich's equation exhibits higher value than Langmuir's (i.e. 0.975 and 0.969 , respectively). However, in the broader perspective, both values appeared relatively higher than 0.9. Therefore, copper adsorption on Prosopis juliflora was fitted with both adsorption isotherms i.e. each site of a Prosopis juliflora can accommodate one molecule of copper ion or it is characterized by supporting surfaces of different affinity (heterogeneity of surfaces of Prosopis juliflora).

\subsubsection{Zn(II) Ions Adsorption Isotherms}

The study was carried out by using $0.5 \mathrm{~g}, 1 \mathrm{~g}, 2 \mathrm{~g}, 3 \mathrm{~g}, 4 \mathrm{~g}$ and $5 \mathrm{~g}$ dose of Prosopis juliflora. Figure 11 shows the relationship between the quantity of $\mathrm{Zn}$ (II) adsorbed per gram of adsorbent and the equilibrium liquid phase concentration at room temperature. Adsorption equilibrium isotherm models were used describe the adsorption process and the results obtained were analyzed using different isothermal equations. The graph obtained by Langmuir equation shows the relation between $1 / \mathrm{Ce}$ in the $\mathrm{x}$ axis and $1 /$ qe in the $y$ axis. On the other hand, the graph of Fruendlich's equation shows the relationship between $\log \mathrm{Ce}$ in the $\mathrm{X}$ axis and log qe in the $\mathrm{y}$ axis.

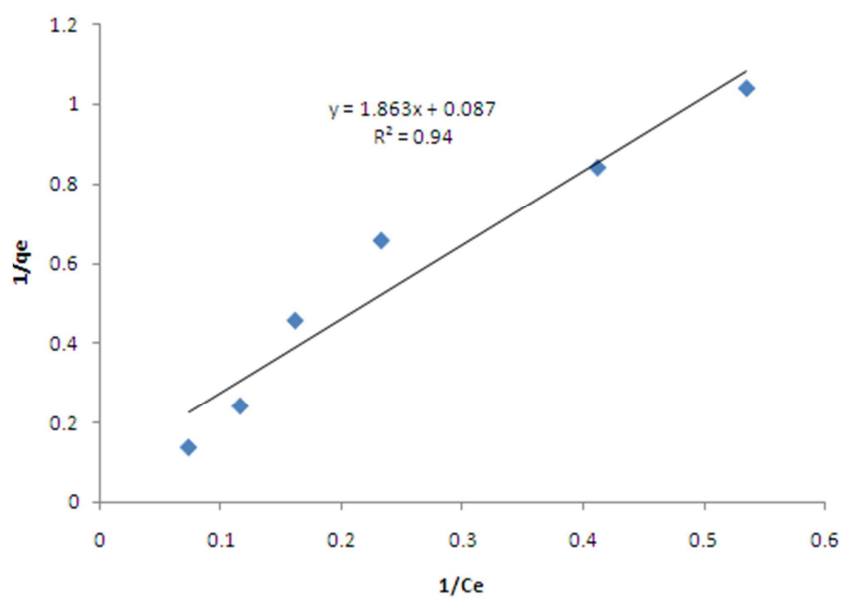

Figure 1. Langmuir adsorption isotherm of Zn(II) ions. Accor
11.5

Slope $\left(1 / \mathrm{bq}_{\mathrm{m}}\right)=1.863, \mathrm{bq}_{\mathrm{m}}=0.5368$,

Langmiur's equation,

$$
\mathrm{qe}=0.5368 \mathrm{Ce} /(1+0.04668 \mathrm{Ce})
$$

Using Langmiur's equation, the maximum adsorption capacity by Prosopis juliflora was obtained as $11.5 \mathrm{mg} / \mathrm{g}$.
That is one gram of the Prosopis juliflora can adsorb 11.5 $\mathrm{mg}$ copper. The value of RL obtained is $1 / 3.334=0.3$. The shape of isotherm by Langmuir's equation was therefore, favorable isotherm. This means that at equilibrium high concentration of copper was adsorbed on Prosopis juliflora surface compared to its amount remained in aqueous solution.

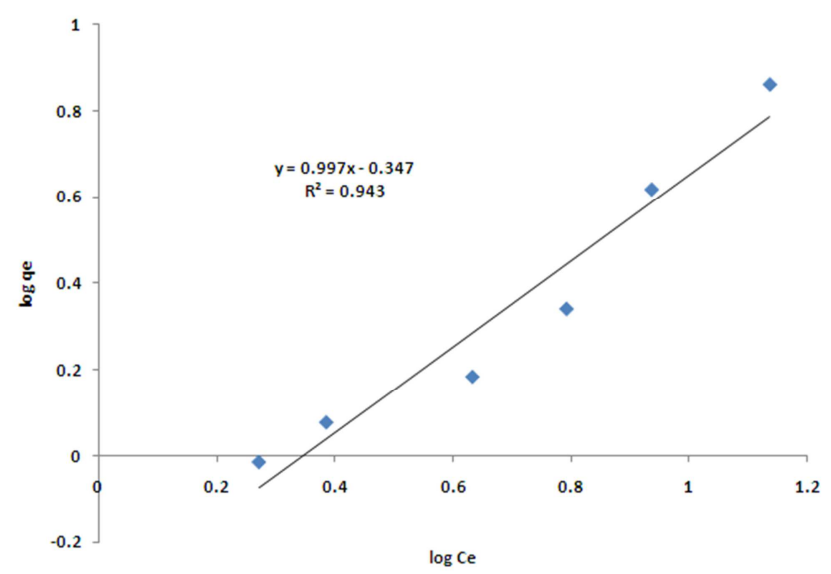

Figure 22. Freundlich adsorption isotherm for Zn(II) ions.

For linearization of the data, the Freundlich equation is written in logarithmic form.

$$
\log \mathrm{x} / \mathrm{m}=\log \mathrm{K}+1 / \mathrm{n} \log \mathrm{Ce}
$$

According to Figure 12:

Slope $1 / \mathrm{n}=0.997$

Intercept $\mathrm{Y}(\operatorname{logk}) \log \mathrm{K}_{\mathrm{f}}=-0.347$

Constant $\mathrm{K}_{\mathrm{f}}=0.45$

Freundlich's equation $\mathrm{q}_{\mathrm{e}}={ }_{\mathrm{f}} \mathrm{Ce}^{1 / \mathrm{n}}=0.45 \mathrm{Ce} \mathrm{e}^{0.997}$

The values of $1 / \mathrm{n}$ and $\mathrm{n}$ obtained from Freundlich's equation were 0.997 and 1.003 respectively. Since the values of $1 / n$ lies between 0 and 1 and $n>1$, it indicates that the Prosopis juliflora can adsorb zinc effectively. From Figures 11 and 12 it can be seen that the Freundlich isotherm represented the experimental data better than Langmuir for zinc (II) ion adsorption with regression coefficient of 0.943 and 0.940 respectively.

Table 1. Langmuir and Freundlich constants for the adsorption of Cu (II) and $\mathrm{Zn}$ (II) ions.

\begin{tabular}{lllll}
\hline Metal ion & Langmuir & & & \\
\hline $\mathrm{q}_{\max }$ & $\mathrm{b}$ & $\mathrm{R}^{2}$ & & \\
$\mathrm{Cu}(\mathrm{II})$ & 18.18 & 0.0336 & 0.969 & \\
$\mathrm{Zn}(\mathrm{II})$ & 11.5 & 0.047 & 0.94 & \\
Freundlich & & & & \\
$\mathrm{R}_{\mathrm{L}}$ & $\mathrm{K}_{\mathrm{f}}$ & $1 / \mathrm{n}$ & $\mathrm{R}^{2}$ & \\
$\mathrm{Cu}(\mathrm{II})$ & 0.373 & 0.547 & 0.992 & 0.975 \\
$\mathrm{Zn}(\mathrm{II})$ & 0.30 & 0.45 & 0.997 & 0.943 \\
\hline
\end{tabular}

$\mathrm{q}_{\max }=$ maximum adsorption capacity $(\mathrm{mg} / \mathrm{g}), \mathrm{b}=$ constant related to binding energy, $\mathrm{R}^{2}=$ correlation coefficient, $\mathrm{R}_{\mathrm{L}}=$ separation factor, $\mathrm{K}_{\mathrm{f}}=$ Freundlich adsorption capacity, $\mathrm{n}=$ Freundlich constant related to intensity of adsorption. 
Table 2. Comparison of the Adsorption capacities (qmax) of $\mathrm{Cu}$ (II) ions using different adsorbents.

\begin{tabular}{lll}
\hline Adsorbent & $\begin{array}{l}\text { Adsorption } \\
\text { capacity }(\mathbf{m g} / \mathbf{g})\end{array}$ & References \\
\hline Dried sunflower leaves & 89.37 & {$[28]$} \\
Sour orange residue & 21.70 & {$[29]$} \\
Papaya wood & 19.88 & {$[30]$} \\
Pomegranate peel & 1.32 & {$[5]$} \\
Coconut Shell Powder & 7.413 & {$[31]$} \\
Mango biomass & 18.93 & {$[32]$} \\
Potato peel & 0.3877 & {$[33]$} \\
Dicliptera bupleuroides Leaves & 1.06 & {$[34]$} \\
Urtica dioica Leaves & 1.49 & {$[35]$} \\
Prosopis juliflora powder & 18.18 & Present study \\
\hline
\end{tabular}

Table 3. Comparison of the Adsorption capacities (qmax) of Zn (II) ions using different adsorbents.

\begin{tabular}{lll}
\hline Adsorbent & $\begin{array}{l}\text { Adsorption } \\
\text { capacity (mg/g) }\end{array}$ & References \\
\hline Dicliptera bupleuroides Leaves & 2.55 & {$[34]$} \\
Mango biomass & 18.93 & {$[33]$} \\
Bentonite and & 79.2 & {$[36]$} \\
kaolinite & 6.35 & {$[35]$} \\
Urtica dioica Leaves & 1.039 & {$[31]$} \\
Coconut Shell Powder & 7.413 & Present study \\
Prosopis juliflora powder & 11.50 & \\
\hline
\end{tabular}

The comparison of adsorbent capacity of Prosopis juliflora with other materials reported in literature is given in Table 2 and 3. Accordingly, the adsorption capacity of Prosopis juliflora powder obtained is good in comparison with the various low cost adsorbents.

\section{Conclusion}

The Results obtained strongly demonstrated from batch adsorption studies that $\mathrm{pH}$, biomass dose, initial metal concentration and contact time affect the metal ions uptake capacity of biosorbents. The effect of adsorbent dosage on the adsorption of metals showed that the percentage of metal removed increased with increase in adsorbent dosage due to increased adsorption surface area. For all the adsorbents studied adsorbent dosage of $10 \mathrm{~g} / \mathrm{L}$ was used as optimum dosage for adsorption of about $80 \%$ of the initial metal concentration. The optimum $\mathrm{pH}$ for the removal of copper $\mathrm{Cu}$ (II) was 5 and 6 for zinc (II). The amount of the metal removed at optimum $\mathrm{pH}$ increased with increase in initial metal concentration but the percentage adsorbed decreased with increase in initial metal concentration due to limited number of active sites.

The maximum uptake capacity for $\mathrm{Cu}$ (II) was $18.18 \mathrm{mg} / \mathrm{g}$ at $\mathrm{pH} 5$ and for $\mathrm{Zn}$ (II) $11.5 \mathrm{mg} / \mathrm{g}$ at PH 6, with $1 \mathrm{~g}$ of adsorbent in $100 \mathrm{~mL}$ of $50 \mathrm{mg} / \mathrm{L}$ initial metal ion concentration for 90 min. The adsorption equilibrium data obtained for removal of $\mathrm{Cu}$ (II) and $\mathrm{Zn}$ (II) on Prosopis juliflora powder at a fixed initial concentration and varying adsorbent dose well fitted into the Langmuir and Freundlich adsorption isotherms, but with higher correlation coefficient for Freundlich model, which shows the adsorption is homogenous. Prosopis juliflora can be a novel adsorbent according to results obtained in this study. It is recommendable to use this weed as an adsorbent as it is obvious of solving two problems with one cure.

\section{References}

[1] Volesky, B., 2007. Biosorption and me. Water Research. 41: 4017-4029.

[2] Gadd, G. M., 2004. Microbial influence on metal mobility and application for bioremediation. Geoderma. 122: 109-119.

[3] Anirudhan, T. S. and P. G. Radhakrishman, 2008. Thermodynamics and kinetics of adsorption of $\mathrm{Cu}$ (II) from aqueous solutions onto a new cation exchanger derived from tamarind fruit shell. J. Chem. Thermodynamics. 40: 702-709.

[4] Ko, D., J. F. Porter and G. Mckay, 2000. Optimized Correlation for the Fixed Bed Adsorption of Metal Ions on Bone Char. Chem. Engineering. Sci. 55: 5819-5829.

[5] El-Ashtoukhy, E. S., N. K. Amin and O. Abdelwahab, 2008. Removal of lead (II) and copper (II) from aqueous solution using pomegranate peel as a new adsorbent. Desalination. 223: $162-173$

[6] Abdel-Shafy, H. I. and O. A. Raouf, 2007. Wastewater reuserisk assessment, decision making and environmental security. Springer Netherlands. 37: 53-82.

[7] Heidari, A., Younesi, H., Mehraban, Z. and Heikkinen, H. (2013) Selective Adsorption of $\mathrm{Pb}$ (II), Cd(II), and Ni(II) Ions from Aqueous Solution Using Chitosan-MAA Nanoparticles. International Journal of Biological Macromolecules, 61, 251263.

[8] Davis, T. A., B. Volesky and R. Vieira, 2001. Sargassum seaweed as biosorbent for heavy metals. Water Research. 34: 4270-4278.

[9] Saravanan, A. and V. Brindha, 2009. An evaluation of chromium and zinc biosorption by a sea weed (Sargassum species) under optimized conditions. Indian Sci. and Technology. 19: 2-11.

[10] Eneida, S. C., and T. M. Ravagnani, 2002. Biosorption of chromiurn (III) by Sargassumspecie Biomass. Electronic J. of Biotechnolgy. 21: 5-12.

[11] Fatima, B., K. Sara, J. Anwar, M. Hassan, R. F. Hafza and H. N. Khalid., 2009. Removal of chromium (VI) by biosorption of Eucalyptus Bark. World applied sci. J. 6(12): 16-38.

[12] Martinez, M., N. Miralles and J. Poch, 2006. Removal of lead (II) and cadmium (II) from aqueous solutions using grape stalk waste. J. of Hazardous Materials. B133: 203-211.

[13] Pino, G. H., M. L. Torem, and G. A. Pinto, 2006. Biosorption of cadmium by green coconut shell powder. Minerals Engineering. 19: 380-387.

[14] Han, R., J. Zhang and H. Liu, 2006. Biosorption of copper (II) and lead (II) aqueous solution by chaff in a fixed bed column. J. of Hazardous Materials. B133: 262-268.

[15] Vijayaraghavan, K., K. Palanivelu and M. Velan, 2006. Biosorption of copper (II) and cobalt (II) from aqueous solutions by crab shell particles. Bioresource Technology. 97: 1411-1419. 
[16] Kumar, Y. P, P. King and R. K. Prasad, 2006. Removal of copper from aqueous solution using Ulva fasciata species. A marine green algae. J. of Hazardous Materials. 137: 367-368

[17] Li, X., Liu, S., Na, Z., Lu, D. and Liu, Z. (2013) Adsorption, Concentration, and Recovery of Aqueous Heavy Metal Ions with the Root Powder of Eichhornia crassipes. Ecological Engineering, 60, 160-166.

[18] Felker, P., and Guevara J. 2003. Potential of Commercial Hardwood Forestry Plantations in Arid-Lands: an Economic Analysis of Prosopis Lumber Production in Argentina and the United States. Forest Ecology and Management 186: 271-286.

[19] Pasiecznik, N. 2001. The Prosopis juliflora-Prosopis pallid Complex: A Monograph.

[20] Witt, A. 2010. Biofuels and Invasive Species from an African Perspective-a Review. GCB Bioenergy. 2: 321-329.

[21] Million M. and Belesti. L. 2014. Removal of Methylene Blue (Mb) Dye from Aqueous Solution by Bioadsorption onto Untreated Parthenium hystrophorous Weed. Mod Chem appl., 2: 4 .

[22] Pavasant, P., R. Apiratikul and T. F. Marhaba, 2006 Biosorption of $\mathrm{Cu}^{2+}, \mathrm{Cd}^{2+}, \mathrm{Pb}^{2+}$ and $\mathrm{Zn}^{2+}$ Using Dried Marine Green Macroalga caulerpa lentillifera. Bioresource Technology. 97: 2321-2329.

[23] Bello, O. S., A. 1. Adeogun, C. J. Ajaelu and E. O. Fehintola, 2008. Adsorption of methylene blue onto activated carbon derived from periwinkle shells. Kinetics and equilibrium studies. Chem. Ecol. 24: 285-295.

[24] Dorris, K. L., B. Yu, Y. Zhang, A. Shukla and S. S. Shukla, 2000. The removal of heavy metal from aqueous solutions by sawdust adsorption-removal of copper. J. Hazardous Materials. B80: 33-42.

[25] Low, K. S., C. K. Lee and K. P. Lee, 1993. Sorption of copper by dye-treated oil-palm fibers. Bioresour. Technology. 44: 109-112.

[26] Chang, J., R. Law and C. Chang, 1997. Biosorption of lead, copper and cadmium by biomass of Pseudomonas aeruginosa. Water Resource. 31: 1651-1658.

[27] Freundlich, H., 1907. Ueber die Adsorption in Loesungen. Z. physik Chem. 57: 385-470.

[28] Benaissa, H. and M. A. Elouchdi, 2007. Removal of copper ions from aqueous solutions by dried sunflower leaves. Chem. Engineering and Processing. 46: 614-622.

[29] Khormaei, M., B. Nasernejad, M. Edrisi and T. Eslamzadeh, 2007. Copper biosorption from aqueous solutions by sour orange residue. $J$. of Hazardous Materials. 149: 269-274.

[30] Saeed, A., M. W. Akhter and M. Iqbal, 2005. Removal and recovery of heavy metals from aqueous solution using papaya wood as a new biosorbent. Separation Purification Technology. 45: 25-31.

[31] Murthy, C. R., P. Ramesh and A. Ramesh, 2011. Study of Biosorption of $\mathrm{Cu}(\mathrm{II})$ from Aqueous Solutions by Coconut Shell Powder. Chemical Sci. J. 17: 1-15.

[32] Ashraf, M. A., M. J. Maah, I. Yusoff, 2010. Study of mango biomass (Mangifera indica L) as a cationic biosorbent. Int. J. Environmental. Sci. Technology. 7 (3): 581-590.

[33] Priyanka T., Mahesh C. V., Joshi S. K., Rajesh K. and Bhandari N. S. (2017). Equilibrium and Thermodynamic Studies of $\mathrm{Pb}(\mathrm{II}), \mathrm{Cu}(\mathrm{II})$ and $\mathrm{Zn}$ (II) Adsorption onto Dicliptera bupleuroides Leaves. Chem Sci Trans., 6(1), 97-106.

[34] Priyanka T., Mahesh C. Vi., Sushil K. J., Harish S., Narendra S. B. (2017). Adsorption of $\mathrm{Pb}$ (II), $\mathrm{Cu}$ (II), and $\mathrm{Zn}$ (II) Ions onto Urtica dioica Leaves (UDL) as a Low Cost Adsorbent: Equilibrium and Thermodynamic Studies. Modern Chemistry. Vol. 5 (1).

[35] Wencui C., Yanfang H., Shengpeng S., Guihong H., Jiongtian L., and Yijun C. (2017). Adsorption Behavior Of Zn (II) Onto Natural Minerals In Wastewater. A Comparative Study of Bentonite and Kaolinite. Physicochem. Probl. Miner. Process, 53(1), 264-278. 